\title{
Erratum to: Aiming to Preserve Pulmonary Valve Function in Tetralogy of Fallot Repair: Comparing a New Approach to Traditional Management
}

Danielle Gottlieb Sen ${ }^{1,2} \cdot$ Marc Najjar $^{1} \cdot$ Betul Yilmaz $^{3,4} \cdot$ Stéphanie M. Levasseur $^{1}$ • Bindu Kalessan $^{1} \cdot$ Jan M. Quaegebeur ${ }^{1} \cdot$ Emile A. Bacha $^{1}$

Published online: 12 April 2016

(c) Springer Science+Business Media New York 2016

\section{Erratum to: Pediatr Cardiol}

\section{DOI 10.1007/s00246-016-1355-1}

The original version of this article unfortunately contained a mistake in the author's group. The family name of "Betul Yilmaz" was misspelled as "Betul Yimaz". The co-author name is corrected with this erratum.

The online version of the original article can be found under doi:10.1007/s00246-016-1355-1.

Emile A. Bacha

eb2709@cumc.columbia.edu

Marc Najjar

mn2594@cumc.columbia.edu

1 Pediatric Cardiac Surgery, Morgan Stanley Children's Hospital of New York-Presbyterian, Columbia University, New York, NY, USA

2 Pediatric Cardiac Surgery, New Orleans Children's Hospital, New Orleans, LA, USA

3 Pediatric Cardiology, Morgan Stanley Children's Hospital of New York-Presbyterian, Columbia University, New York, NY, USA

4 Pediatric Cardiology, Texas Children's Hospital, Houston, TX, USA 